\title{
The Prevalence of Chronic Obstructive Pulmonary Disease by the Global Lung Initiative Equations in North-Western Russia
}

\author{
Elena Andreeva ${ }^{a, c}{\text { Marina Pokhaznikovad }{ }^{d} \text { Anatoly Lebedev }}^{d}$ Irina Moiseeva ${ }^{d}$ \\ Olga Kutznetsovad Jean-Marie Degryse ${ }^{a, b}$ \\ ${ }^{a}$ Institute of Health and Society, Université Catholique de Louvain, Brussels, and ${ }^{b}$ Department of Public Health and \\ Primary Care, KU Leuven, Leuven, Belgium; ' ${ }^{\mathrm{C}}$ epartment of Family Medicine, Northern State Medical University, \\ Arkhangelsk, and ${ }^{\mathrm{d}}$ Department of Family Medicine, North-Western State Medical University (named after I.I. \\ Mechnikov), Saint Petersburg, Russia
}

\section{What Is the Key Question?}

- What is the prevalence of airflow obstruction in adults aged 35-70 years in two north-western cities in Russia, a country where smoking rates are among the highest in the world?

\section{What Is the Bottom Line?}

- The spirometrically defined chronic obstructive pulmonary disease prevalence was $6.8 \%$ by a fixed (0.7) and $4.8 \%$ by the Global Lung Initiative 2012 lower limit of normal cut-off, which is lower than what was reported in neighbouring countries, and should be put in perspective of the high cardiovascular mortality rates in this part of Russia.

\section{Why Read on?}

- In this first population-based prevalence study in the Russian Federation, we also found that $22.5 \%$ of participants with airflow obstruction had findings of asthma-chronic obstructive pulmonary disease overlap syndrome, and $1 \%$ presented a paradoxical bronchodilator response.

\section{Key Words}

Epidemiology of chronic obstructive pulmonary disease and asthma - Chronic obstructive pulmonary disease . Tobacco $\cdot$ Spirometry reference values

\begin{abstract}
Background: The prevalence of chronic obstructive pulmonary disease (COPD) varies in different countries, while the cut-off for airflow obstruction (AO) is still contested. No COPD prevalence data based on the Global Lung Initiative (GLI) 2012 equations are available in Russia. Objectives: This
\end{abstract}

\section{KARGER}

E-Mail karger@karger.com www.karger.com/res
(2) 2016 S. Karger AG, Basel

0025-7931/16/0911-0043\$39.50/0
Prof. Jean-Marie Degryse

Institute of Health and Society

Université Catholique de Louvain

Clos Chapelle-aux-Champs 30, BE-1200 Brussels (Belgium)

E-Mail jean-marie.degryse@ uclouvain.be 
study aims to assess AO prevalence by the GLI lower limit of normal (GLI-LLN) and the fixed cut-off, to identify AO risk factors and to assess the diagnostic value of respiratory symptoms in north-western Russia. Methods: In a north-western Russian population-based sample of 2,974 adults aged 3570 years, data on socio-demographics, smoking, occupational exposures and respiratory symptoms were collected, and spirometry was performed before and after bronchodilator (BD) administration. Results: The AO prevalence was $6.8 \%(95 \% \mathrm{Cl} 5.8-7.9)$ based on the fixed and $4.8 \%(95 \% \mathrm{Cl}$ 3.9-5.7) based on the GLI-LLN cut-off. $22.5 \%$ of the participants with post-BD AO had a positive bronchodilator test, and $1 \%$ showed a paradoxical $B D$ response. Of the environmental factors studied, only smoking was independently associated with AO (odds ratio $2.47,95 \% \mathrm{Cl} 1.60-3.82$ ). The positive predictive value of respiratory symptoms for $\mathrm{AO}$ was $11 \%$ based on the fixed and $8 \%$ based on the GLI-LLN cut-off. Conclusions: In a sample of adults in north-western Russia, the AO prevalence by the GLI-LLN cut-off was lower than that by the fixed cut-off. The predictive value of respiratory symptoms was low.

(c) 2016 S. Karger AG, Basel

\section{Introduction}

Chronic obstructive pulmonary disease (COPD) remains a major public health problem in the 21 st century [1]. There is a significant heterogeneity in COPD prevalence that might be explained by a diversity of methodological approaches to the definition and diagnosis of COPD in different studies as well as by the different age and sex distributions of sampled populations [2-4]. Most of the individuals with COPD (70-90\%) are undiagnosed; therefore, they do not receive appropriate medical care and continue to smoke and/or be exposed to other COPD risk factors [5].

COPD diagnosis requires a comprehensive approach that considers clinical signs and symptoms, risk factors and spirometry [6]. COPD diagnoses based only on symptoms or patient-reported diagnoses underestimate its prevalence. The positive predictive value (PPV) of signs and symptoms for a diagnosis of chronic airflow obstruction $(\mathrm{AO})$ is low in unselected populations [7-9].

Spirometry provides better estimates of the AO prevalence, but it has some limitations [3]. Subjects with comparable AOs have different phenotypes, with marked differences in age, symptoms, comorbidities and predicted mortalities [10].
Also, the appropriate cut-off value of the ratio of forced expiratory volume in $1 \mathrm{~s}$ to forced vital capacity $\left(\mathrm{FEV}_{1} /\right.$ FVC) used to define AO is still contested $[11,12]$. Although both the fixed ratio (0.7) and the lower limit of normal (LLN) cut-offs are related to clinically relevant outcomes, there is no clear preference for one over the other [13].

Variable prevalence rates of COPD in Russia are reported, but there are no COPD or AO prevalence data using the Global Lung Initiative (GLI) 2012 reference equations [14].

The aims of this study are to assess the prevalence of AO in adults aged 35-70 years in two north-western cities in Russia based on the fixed (0.7) and the GLI-LLN cutoffs, to identify risk factors for $\mathrm{AO}$ using both cut-offs and to assess the diagnostic value of respiratory symptoms for AO.

\section{Methods}

Study Design and Population

The RESPECT (RESearch on the PrEvalence and diagnosis of COPD and its Tobacco-related aetiology) study is a populationbased study set up in collaboration with the Université Catholique de Louvain (Belgium), the North-Western State Medical University (named after I.I. Mechnikov), St. Petersburg (Russia) and the Northern State Medical University, Arkhangelsk (Russia). The study was designed to attain a better understanding of the epidemiology of COPD in north-western Russia.

A description of the design and rationale of the RESPECT study has previously been published elsewhere [15]. Briefly, 15 primary care centres in two north-western Russian cities (St. Petersburg and Arkhangelsk) were invited to participate in the RESPECT study, and 15 investigators (10 from St. Petersburg and 5 from Arkhangelsk) were recruited.

The study population was randomly selected from lists (organized based on territories) provided by the 15 participating centres. Adults 35-70 years of age were selected from each centre using a random number generator and were subsequently invited to participate in the study. The participating sites agreed to recruit a population-based random sample of at least 200 adults who were not institutionalized, were aged 35-70 years and were living in a well-defined administrative area [15]. The research investigators administered questionnaires regarding the participants' background characteristics, including sociodemographic data, smoking status, occupational exposures and respiratory symptoms. All participants were invited to have spirometry. The local medical ethics review boards approved the study protocol [North-West State Medical University (named after I.I. Mechnikov), St. Petersburg, protocol No. 11 from December 7, 2011, and Northern State Medical University, Arkhangelsk, protocol No. 01/1-12 from January 11, 2012]. All participants provided informed consent. Patients were enrolled between June 8, 2012, and December 27, 2013.
44

Respiration 2016;91:43-55 DOI: $10.1159 / 000442887$
Andreeva/Pokhaznikova/Lebedev/

Moiseeva/Kutznetsova/Degryse 


\section{Background Characteristics and Other Variables}

The background characteristics included variables such as sex, age and sociodemographic status. Smoking status was specified as 'never smoked', 'former smoker' (quit smoking 6 months or more previously), or 'current smoker'.

The American Thoracic Society (ATS) 1978 Adult Questionnaire (ATS-DLD-78) was used to assess the exposure to occupational hazards [16]. The participants were asked about their use of personal gas or wood stoves to estimate their indoor exposure to biomass fuels [17]. The gas stove utilization ratings were as follows: 'none', 'low use' (1-6 times/week) or 'high use' ( $>7$ times/week). Similar ratings were used for wood stove utilization: 'none', 'low use' (1-4 times/week) or 'high use' ( $>5$ times/week).

Information regarding each individual's history of obstructive airway disease (asthma, chronic bronchitis, emphysema, chronic cough and allergic rhinitis), tuberculosis anamnesis and comorbidities was collected in a systematic manner.

The participants were asked about the presence of chronic cough, sputum production (defined as lasting longer than 3 months) and dyspnoea as chronic respiratory symptoms [18].

\section{Spirometry}

Spirometry was performed with a portable turbine Micro Spirometer (MIR Spirobank, Rome, Italy) and a personal computer equipped with the WiPam program to facilitate the uploading of data to a central database. The accuracy of the spirometry, which was performed by trained investigators, has been previously reported [19].

All investigators were invited to participate in a 3-week distance-learning course on spirometry with a 1-day face-to-face session (SpiroCourse) [20]. All investigators completed the course successfully and agreed to receive continuous quality feedback on the examinations.

The ATS/European Respiratory Society (ERS) quality criteria were used to assess the acceptability and repeatability of the results [21]. After the assessment, all spirometry results were evaluated by 2 independent judges and classified according to 4 categories: ATS1, all ATS/ERS criteria, including reproducibility, were satisfied; ATS2, all criteria, except for duration of expiration $>6 \mathrm{~s}$, were satisfied; ATS3, the test was 'usable' for the interpretation of the peak expiratory flow and $\mathrm{FEV}_{1}$, and the spirograms displayed good starts and no cough was noted during the 1st second of the manoeuvre; ATS4, none of the ATS/ERS criteria were satisfied, and the spirograms were not usable. Spirograms scored as ATS1 or ATS2 were considered to be of acceptable quality.

Winspiro Pro software (MIR) was used to compare the measured values with those in reference tables and to automatically calculate the reproducibility of the performed spirometry, in accordance with the ERS guidelines. Pre- and post-bronchodilator (BD) spirometry test results were recorded. Using $400 \mu \mathrm{g}$ of salbutamol or $160 \mu \mathrm{g}$ of ipratropium bromide [for the patients older than 60 years of age or with comorbid cardiovascular disease $(\mathrm{CVD})$ ], reversibility testing was offered to all participants. The second spirometry test was performed 15 (for salbutamol) or 45 min (for ipratropium bromide) after the first spirometry test. Reversible AO was defined according to the ATS/ERS criteria ( $>12 \%$ and $200 \mathrm{ml}$ increase in $\mathrm{FEV}_{1}$ after BD administration). The ATS/ ERS quality criteria were used to assess the acceptability and repeatability of the results [21].

The predictive values for the spirometry parameters were calculated based on the GLI 2012 reference data using GLI 2012
Data Conversion software [22]. COPD was defined as $\mathrm{FEV}_{1} / \mathrm{FVC}$ $<0.7$ (fixed cut-off) and $\mathrm{FEV}_{1} / \mathrm{FVC}<\mathrm{GLI}-\mathrm{LLN}$ (5th percentile of the $\mathrm{Z}$ scores of the GLI 2012 reference values) on the post-BD values.

\section{Sensitivity Analysis}

In order to test the robustness of our prevalence figures, we additionally performed a sensitivity analysis. Three different adjustment methods were used to assess the potential non-participation bias: (1) transformation of the observed prevalence in each age group using an index that is proportional to the relative weight of the age group in the general population in order to recalculate overall prevalence; (2) adaptation of the sample by 'at random' elimination of cases in the strata that are overrepresented (55-64 and 65-70 years old), and (3) simulation of the impact on the overall prevalence (or on the prevalence in different strata) starting from two hypotheses: (a) all of the non-responders are smokers, and (b) none of the non-responders are smokers, by using the average number of diagnosis of $\mathrm{AO}$ in smokers and non-smokers to adjust the prevalence. The age and sex distribution in the RESPECT study and in the general population were compared in detail earlier [15].

\section{Statistical Analysis}

Descriptive statistics were calculated for all variables, with the continuous variables presented as the mean \pm standard deviation (SD) and the categorical variables presented as numbers and frequencies. The baseline variables were compared across the three groups with one-way ANOVA, and Pearson's $\chi^{2}$ test was carried out for the categorical variables. Multivariable logistic regression was used to estimate the association between $\mathrm{AO}$ and predictors (adjusted in three consecutive steps for potential confounders). Statistical significance was set at $<0.05$ (a two-tailed probability value).

Based on the two $\mathrm{FEV}_{1} / \mathrm{FVC}$ cut-offs, the study population was divided into three $\mathrm{AO}$ categories: (1) participants with $\mathrm{FEV}_{1} / \mathrm{FVC}$ $\geq 0.70$ and $\geq$ GLI-LLN (no AO according to either cut-off); (2) participants with $\mathrm{FEV}_{1} / \mathrm{FVC}<0.7$ and $\geq$ GLI-LLN (the discordant group; $\mathrm{AO}$ according to the fixed cut-off only), and (3) participants with $\mathrm{FEV}_{1} / \mathrm{FVC}<0.70$ and $<$ GLI-LLN (AO according to both cutoffs). The only 2 participants with $\mathrm{FEV}_{1} / \mathrm{FVC} \geq 0.70$ and $<\mathrm{GLI}-$ LLN were excluded from this analysis.

SPSS version 20.0 (SPSS Inc., Chicago, Ill., USA) was used for the statistical analysis.

\section{Results}

Out of the 4,419 individuals who were invited to participate in the RESPECT study, 3,133 agreed to participate and met the inclusion criteria. Satisfactory quality of spirometry (after comprehensive assessments for reproducibility and acceptability) was achieved by 2,974 participants before and by 2,388 after the BD test (fig. 1,2). The mean age of the RESPECT study population was 54 years (SD, 9.25); $31.8 \%$ were male, and $47.8 \%$ were current or ex-smokers. The background characteristics of the 


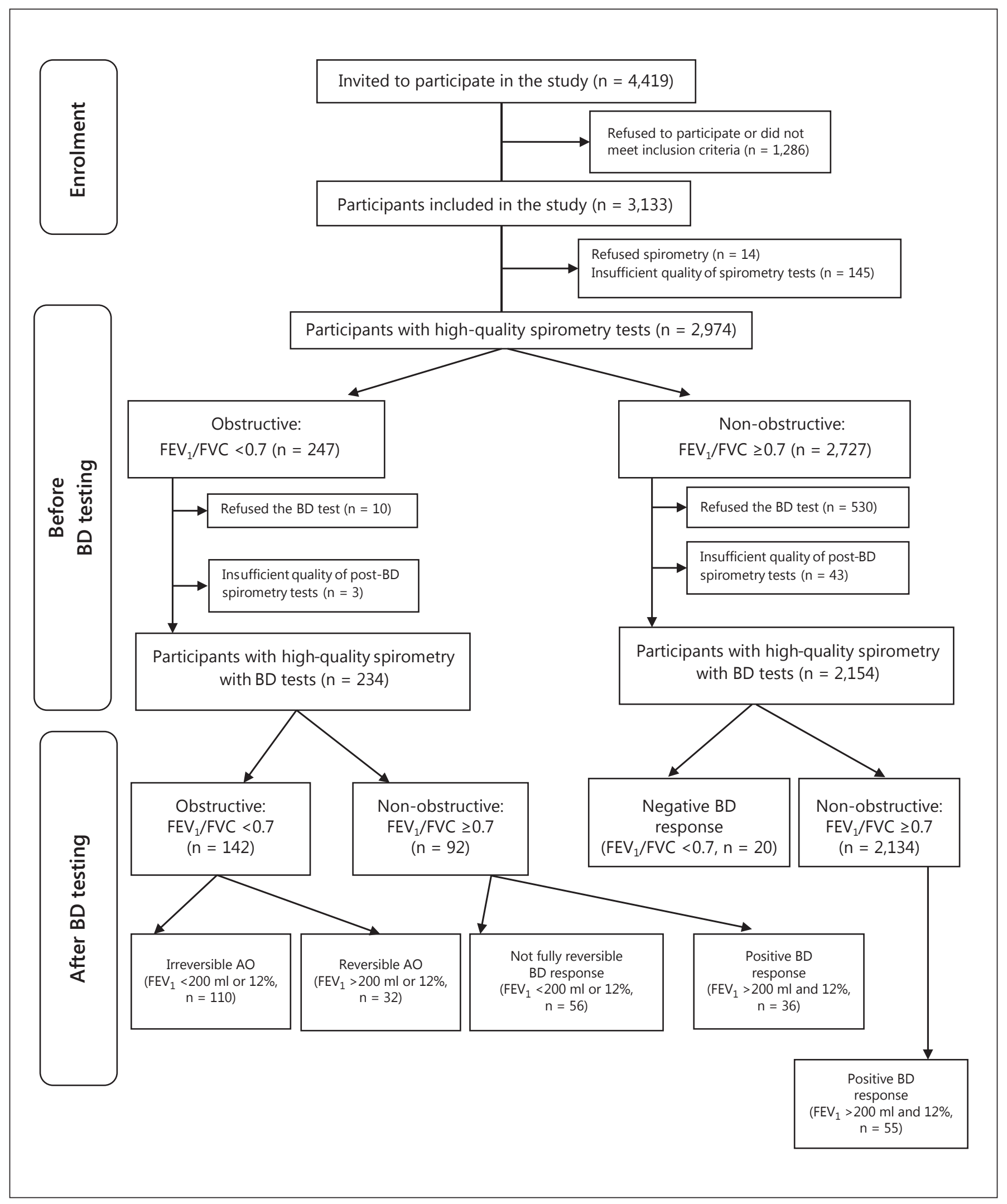

Fig. 1. RESPECT flow diagram (obstruction based on the fixed ratio $\mathrm{FEV}_{1} / \mathrm{FVC}<0.7$ ). 


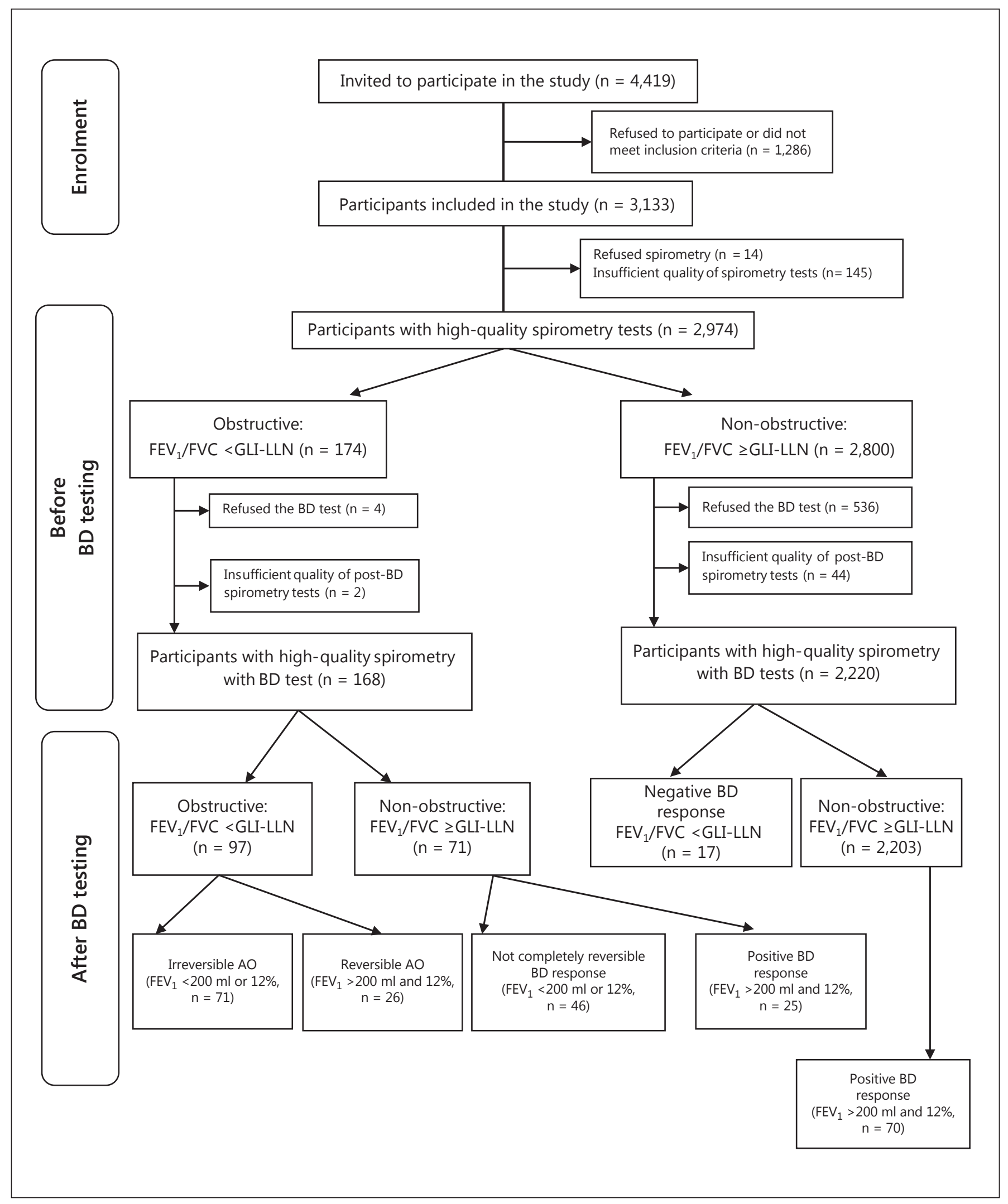

Fig. 2. RESPECT flow diagram (obstruction based on the ratio $\mathrm{FEV}_{1} / \mathrm{FVC}<\mathrm{GLI}-\mathrm{LLN}$ ).

Prevalence of COPD in North-Western Russia 
Table 1. Baseline characteristics of the total population after BD testing and across categories based on the two cut-offs

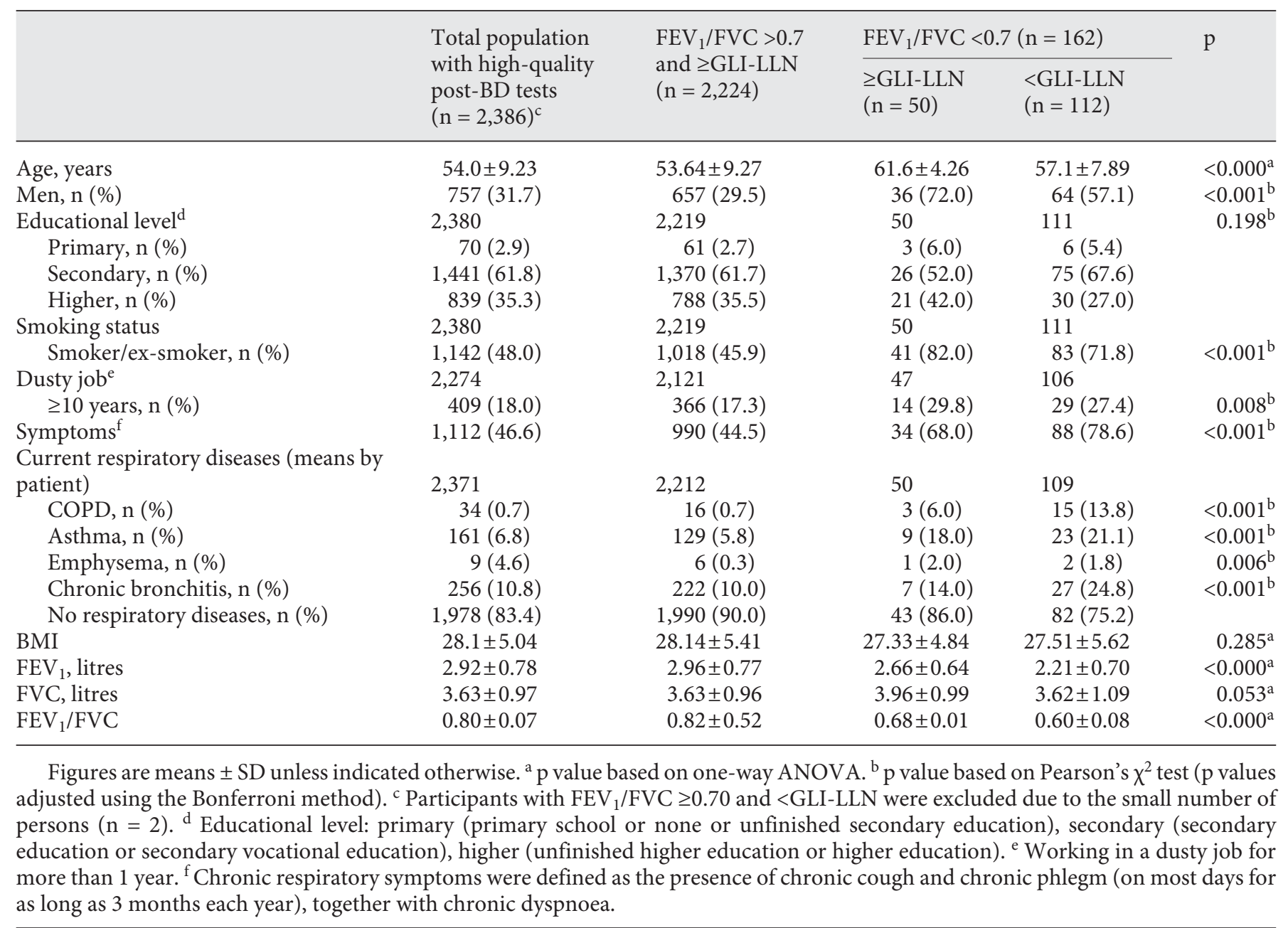

RESPECT population are presented in the online supplementary appendix 1 (for all online suppl. material, see www.karger.com/doi/10.1159/000442887). The RESPECT population includes more women than the average population in the north-west region ( 68.2 vs. $55.3 \%$; $\mathrm{p}<0.05)$ as well as more participants aged $55-70$ years (53.7 vs. $35.3 \%$; $\mathrm{p}<0.05$ ) [15].

The baseline characteristics of the total study population with the BD test and three AO categories based on fixed and GLI-LLN cut-offs are presented in table 1.

AO prevalence was $6.8 \%$ according to the fixed cut-off and $4.8 \%$ according to GLI-LLN. Participants with AO by both cut-offs tended to be male, older, and smokers/exsmokers, were more frequently exposed to dusty jobs and reported chronic respiratory symptoms compared to the participants with no AO. There was no statistically sig- nificant difference between the $\mathrm{AO}$ categories in terms of educational level and body mass index (BMI).

The prevalence of AO (based on pre- and post-BD spirometry) was higher with the fixed cut-off than with the GLI-LLN (table 2a). The overall prevalence of AO (after $\mathrm{BD}$ administration) for men was higher than for women for both cut-offs (table 2a).

Generally, the prevalence of post-BD AO according to both cut-offs increased with age (table 2a), i.e. it was less than $5 \%$ in patients aged $35-44$ years, while in those aged 65-70 years, the prevalence for the fixed and GLI-LLN cut-offs was 26.9 and $15.7 \%$ for men and 4.1 and $2.6 \%$ for women, respectively.

The prevalence of $\mathrm{AO}$, according to the smoking status, is presented in table $2 \mathrm{~b}$. Generally, the prevalence of post-BD $\mathrm{AO}$ increased with an increasing number of
48 
Table 2. AO before and after BD tests

a Based on the two cut-off values by sex and age groups

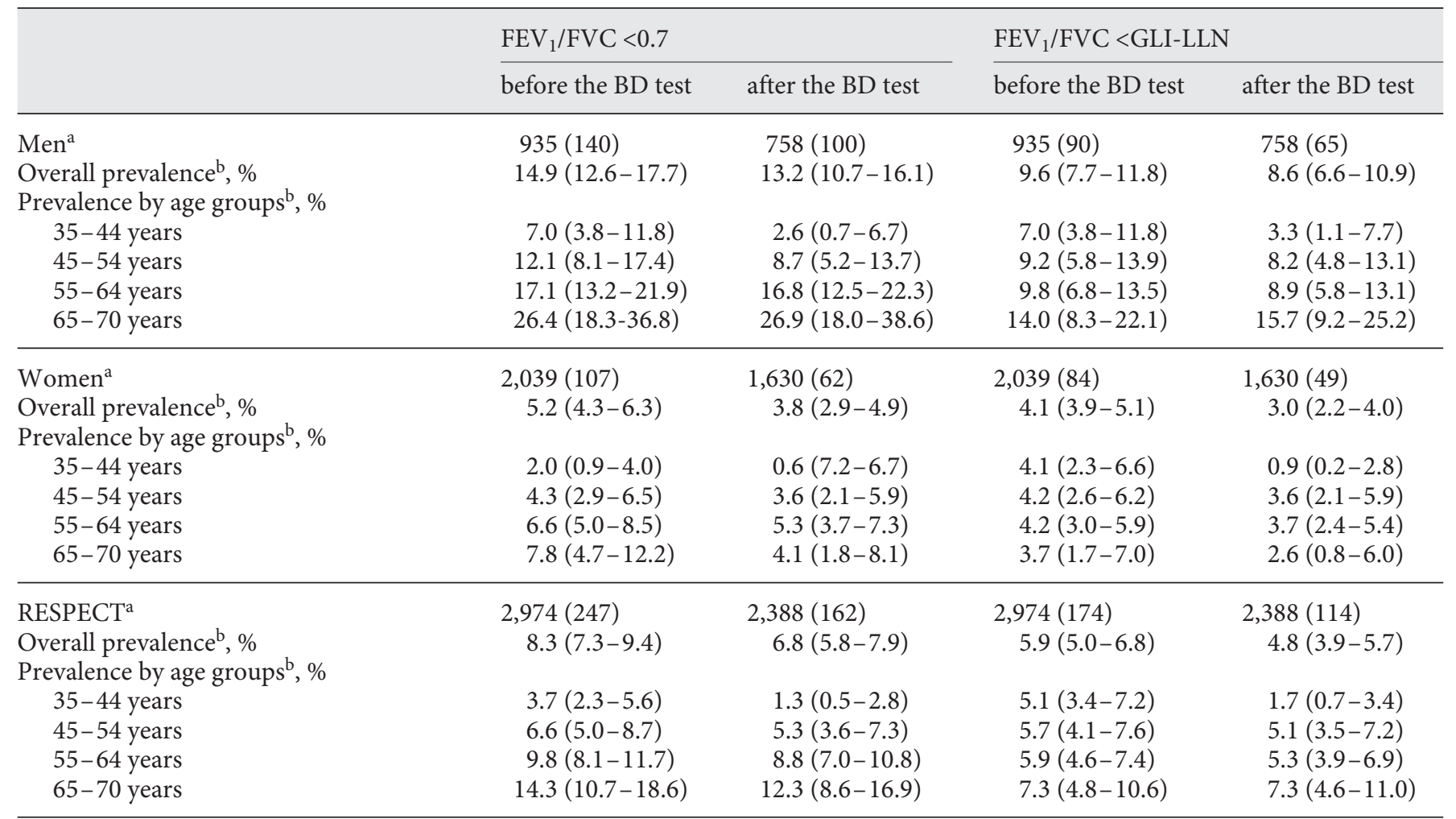

a Total number with number of obstructions in parentheses. ${ }^{b}$ Figures in parentheses indicate $95 \%$ CI.

b Based on the two cut-off values by smoking status

\begin{tabular}{|c|c|c|c|c|}
\hline & before the BD test & after the BD test & before the BD test & after the BD test \\
\hline Overall prevalence $^{\mathrm{b}}, \%$ & $14.9(12.6-17.7)$ & $13.2(10.7-16.1)$ & $9.6(7.7-11.8)$ & $8.6(6.6-10.9)$ \\
\hline \multicolumn{5}{|c|}{ Prevalence by smoking status ${ }^{\mathrm{b}}, \%$} \\
\hline Never & $4.8(2.5-8.4)$ & $4.6(2.1-8.7)$ & $2.8(1.9-3.6)$ & $3.6(1.4-7.4)$ \\
\hline \multicolumn{5}{|c|}{ Prevalence by smoking exposure ${ }^{\mathrm{c}}$} \\
\hline$<10$ pack-years & $10.2(5.4-17.4)$ & $10.6(5.1-19.6)$ & $5.5(2.2 .-11.3)$ & $4.3(1.2-10.9)$ \\
\hline$\geq 10$ and $<20$ pack-years & $8.7(4.6-14.9)$ & $6.3(2.5-13.0)$ & $6.7(3.3-12.3)$ & $5.4(2.0-11.8)$ \\
\hline$\geq 20$ pack-years & $25.4(20.46-30.9)$ & $21.4(16.6-26.7)$ & $16.7(12.6-21.0)$ & $13.7(10.0-18.2)$ \\
\hline Women $^{\mathrm{a}}$ & $2,039(107)$ & $1,630(62)$ & $2,039(84)$ & $1,630(49)$ \\
\hline Ex-smoker & $5.9(3.4-9.5)$ & $5.3(2.7-9.2)$ & $6.3(3.7-10.0)$ & $3.5(1.5-6.9)$ \\
\hline \multicolumn{5}{|c|}{ Prevalence by smoking exposure ${ }^{c}$} \\
\hline$<10$ pack-years & $5.2(3.2-8.1)$ & $3.6(1.8-6.5)$ & $5.0(3.0-7.7)$ & $3.3(1.6-6.0)$ \\
\hline$\geq 10$ and $<20$ pack-years & $8.4(4.6-14.1)$ & $7.1(3.4-13.1)$ & $9.6(5.5-15.6)$ & $6.4(3.0-12.2)$ \\
\hline$\geq 20$ pack-years & $13.2(8.3-20.0)$ & $9.6(5.1-16.3)$ & $9.0(5.0-14.8)$ & $6.6(3.0-12.6)$ \\
\hline
\end{tabular}


Table 2 (continued)

\begin{tabular}{|c|c|c|c|c|}
\hline & \multicolumn{2}{|l|}{$\mathrm{FEV}_{1} / \mathrm{FVC}<0.7$} & \multicolumn{2}{|c|}{$\mathrm{FEV}_{1} / \mathrm{FVC}<\mathrm{GLI}-\mathrm{LLN}$} \\
\hline Overall prevalence ${ }^{\mathrm{b}}, \%$ & $8.3(7.3-9.4)$ & $6.8(5.8-7.9)$ & $5.9(5.0-6.8)$ & $4.8(3.9-5.7)$ \\
\hline \multicolumn{5}{|c|}{ Prevalence by smoking status ${ }^{\mathrm{b}}, \%$} \\
\hline Never & $4.1(3.1-5.2)$ & $3.0(2.1-4.1)$ & $2.6(1.9-3.6)$ & $2.3(1.5-3.3)$ \\
\hline \multicolumn{5}{|c|}{ Prevalence by smoking exposure ${ }^{c}$} \\
\hline$<10$ pack-years & $6.5(4.4-9.1)$ & $5.3(3.3-8.1)$ & $5.1(3.3-7.4)$ & $3.5(1.9-5.9)$ \\
\hline$\geq 10$ and $<20$ pack-years & $8.5(5.6-12.4)$ & $6.8(4.0-10.8)$ & $8.2(5.4-12.0)$ & $6.0(3.3-9.9)$ \\
\hline$\geq 20$ pack-years & $21.7(18.0-26.0)$ & $17.9(14.3-22.1)$ & $14.2(11.2-17.7)$ & $11.7(8.8-15.2)$ \\
\hline
\end{tabular}

${ }^{a}$ Total number with number of obstructions in parentheses. ${ }^{b}$ Figures in parentheses indicate $95 \%$ CI. ${ }^{c}$ One pack-year of smoking indicates that an individual smoked one package of cigarettes (20 cigarettes) daily for 1 year.

Table 3. Multivariable analysis of risk factors for AO by the two cut-offs after BD testing

\begin{tabular}{|c|c|c|c|c|c|c|}
\hline & \multicolumn{6}{|c|}{ AO hazard ratio $(95 \% \mathrm{CI})$} \\
\hline & \multicolumn{3}{|l|}{$\mathrm{FEV}_{1} / \mathrm{FVC}<0.7$} & \multicolumn{3}{|c|}{$\mathrm{FEV}_{1} / \mathrm{FVC}<\mathrm{GLI}-\mathrm{LLN}$} \\
\hline & model 1 & model 2 & model 3 & model 1 & model 2 & model 3 \\
\hline Age & $1.08(1.06-1.10)^{*}$ & $1.08(1.05-1.10)^{*}$ & $1.07(1.05-1.10)^{*}$ & $1.05(1.02-1.07)^{*}$ & $1.05(1.02-1.08)^{*}$ & $1.04(1.01-1.075)^{* *}$ \\
\hline Sex (male) & $2.63(1.84-3.76)^{*}$ & $2.59(1.78-3.76)^{*}$ & $3.06(2.07-4.53)^{*}$ & $2.09(1.39-3.15)^{*}$ & $2.10(1.36-2.23)^{* *}$ & $2.51(1.60-3.95)^{*}$ \\
\hline Smoker/ex-smoker & $3.08(2.05-4.62)^{*}$ & $2.98(1.95-4.53)^{*}$ & $2.47(1.60-3.82)^{*}$ & $2.79(1.75-4.44)^{*}$ & $2.60(1.61-4.20)^{*}$ & $2.06(1.25-3.39)^{* *}$ \\
\hline Dusty work, $>10$ years & & $1.17(0.75-1.82)$ & $1.05(0.67-1.64)$ & & $1.27(0.76-2.12)$ & $1.14(0.66-1.87)$ \\
\hline Gas/chemical fumes at work, $>10$ years & & $1.47(0.95-2.27)$ & $1.40(0.90-2.18)$ & & $1.16(0.69-2.00)$ & $1.09(0.65-1.84)$ \\
\hline Highly exposed to biomass fuel & & $1.61(0.81-3.19)$ & $1.65(0.83-3.30)$ & & $1.04(0.53-2.05)$ & $1.05(0.52-2.09)$ \\
\hline Chronic cough & & & $1.76(1.22-2.53)^{* *}$ & & & $2.10(1.36-3.24)^{* *}$ \\
\hline Chronic dyspnoea & & & $2.23(1.55-3.22)^{*}$ & & & $2.44(1.59-3.76)^{*}$ \\
\hline
\end{tabular}

Model 1: adjusted for age, gender and smoking status; model 2: model 1 adjusted for exposure to dust, gas or chemical fuels at work and exposure to biomass fuels (firewood used

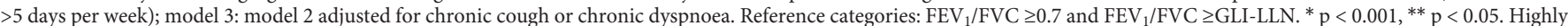
exposed to biomass fuels was defined as higher wood/coal stove use ( $>5$ times/week). Chronic cough was defined as the presence of any cough first thing in the morning or during the day or on most days for as long as 3 months each year. Chronic dyspnoea was defined as the presence of any dyspnoea (shortness of breath when hurrying on level ground or walking up a slight hill or walking with other people of his/her own age on level ground or having to stop for breath when walking at his/her pace on level ground).

pack-years, and among never-smokers it tended to be similar to the prevalence in those with $<10$ pack-years of smoking exposure.

The prevalence of reversible AO for the fixed and GLILLN cut-offs (FEV $1 \geq 12 \%$ and $200 \mathrm{ml}$ after BD) was $1.3 \%$ (95\% CI 0.9-1.9) and 1.1\% (95\% CI 0.7-1.6), respectively (fig. 1, 2).

The results of our sensitivity analysis using three different adjustment methods for modelling non-participation are reported in online supplementary appendix 2 . We found no relevant difference between the global and sex-specific prevalence observed in the RESPECT population, and the estimates after adjustments.

Age, sex and smoking status were risk factors for $\mathrm{AO}$ according to both cut-offs, even after adjusting for occupation (dusty jobs $\geq 10$ years, gas/chemical fume exposure $\geq 10$ years), indoor pollution (significant exposure to biomass fuels) and existing respiratory symptoms (chronic cough and dyspnoea; table 3 ). Dyspnoea was more strongly associated with AO than cough for both cut-offs. There was no association between $\mathrm{AO}$ and any kind of exposure (e.g. occupational hazards and indoor pollution), except for tobacco.

Using the ATS/ERS criteria $\left(\mathrm{FEV}_{1}>12 \%\right.$ and $\left.200 \mathrm{ml}\right)$, approximately $3 \%$ of the participants without AO according to both cut-offs had a 'significant' response to a $\mathrm{BD}$ (fig. 1, 2).

At least $0.97 \%$ (95\% CI $0.60-1.49)$ of the participants without pre-BD AO according to the fixed cut-off and $0.76 \%$ (95\% CI 0.4-1.2) of those according to GLI-LLN demonstrated a negative response after the administration of $\mathrm{BD}\left(\mathrm{FEV}_{1} / \mathrm{FVC}<0.7\right.$ or GLI-LLN; fig. 1,2$)$. 
Table 4. Predictive value of chronic respiratory symptoms for AO by the two cut-offs after BD testing

\begin{tabular}{|c|c|c|c|c|}
\hline & \multicolumn{2}{|l|}{$\mathrm{FEV}_{1} / \mathrm{FVC}<0.70$} & \multicolumn{2}{|l|}{$\mathrm{FEV}_{1} / \mathrm{FVC}<\mathrm{GLI}-\mathrm{LLN}$} \\
\hline & positive & negative & positive & negative \\
\hline \multicolumn{5}{|l|}{ Chronic respiratory symptoms } \\
\hline With symptoms $(\mathrm{n}=1,113)$ & 122 & 991 & 89 & 1,024 \\
\hline No symptoms $(\mathrm{n}=1,275)$ & 40 & 1,235 & 25 & 1,250 \\
\hline Total $(\mathrm{n}=2,388)$ & 162 & 2,226 & 114 & 2,274 \\
\hline Sensitivity (95\% CI), \% & $75.31(67.93-81.74)$ & & $78.07(69.35-85.28)$ & \\
\hline Specificity (95\% CI), \% & $55.48(53.39-57.56)$ & & $54.97(52.90-57.03)$ & \\
\hline $\operatorname{AUC}(95 \% \mathrm{CI})$ & $0.65(0.61-0.69)$ & & $0.66(0.62-0.71)$ & \\
\hline PPV (95\% CI), \% & $10.96(9.19-12.95)$ & & $8.00(6.47-9.75)$ & \\
\hline Negative predictive value (95\% CI), \% & $96.86(95.75-97.75)$ & & $98.04(97.12-98.73)$ & \\
\hline \multicolumn{5}{|l|}{ Chronic cough } \\
\hline With cough $(n=890)$ & 100 & 790 & 74 & 816 \\
\hline No cough $(\mathrm{n}=1,487)$ & 61 & 1,426 & 39 & 1,448 \\
\hline Sensitivity(95\% CI), \% & $62.11(54.14-79.63)$ & & $65.49(55.96-74.18)$ & \\
\hline Specificity (95\% CI), \% & $64.35(62.32-66.35)$ & & $63.96(61.94-65.94)$ & \\
\hline $\operatorname{AUC}(95 \% \mathrm{CI})$ & $0.63(0.59-0.68)$ & & $0.65(0.59-0.70)$ & \\
\hline PPV (95\% CI), \% & $11.24(9.24-13.50)$ & & $8.31(6.58-10.33)$ & \\
\hline Negative predictive value (95\% CI), \% & $95.90(94.76-96.85)$ & & $97.38(96.43-98.13)$ & \\
\hline \multicolumn{5}{|l|}{ Chronic dyspnoea } \\
\hline With dyspnoea $(\mathrm{n}=879)$ & 93 & 786 & 69 & 810 \\
\hline No dyspnoea $(\mathrm{n}=1,498)$ & 68 & 1,430 & 44 & 1,454 \\
\hline Sensitivity (95\% CI), \% & $57.76(49.74-65.50)$ & & $61.06(51.44-70.09)$ & \\
\hline Specificity (95\% CI), \% & $64.53(62.50-66.52)$ & & $64.22(62.21-66.20)$ & \\
\hline AUC $(95 \% \mathrm{CI})$ & $0.61(0.57-0.66)$ & & $0.63(0.57-0.68)$ & \\
\hline PPV (95\% CI), \% & $10.58(8.62-12.80)$ & & $7.85(6.16-9.83)$ & \\
\hline Negative predictive value (95\% CI), \% & $95.46(94.28-96.46)$ & & $97.06(96.08-97.86)$ & \\
\hline
\end{tabular}

Chronic respiratory symptoms were defined as the presence of chronic cough and chronic phlegm on most days for as long as 3 months each year, together with chronic dyspnoea. Chronic cough was defined as the presence of any cough first thing in the morning or during the day or on most days for as long as 3 months each year. Chronic dyspnoea was defined as the presence of any dyspnoea (shortness of breath when hurrying on level ground or walking up a slight hill or walking with other people of his/her own age on level ground or having to stop for breath when walking at his/her pace on level ground).

Eighty-six percent of the participants with $\mathrm{AO}$ according to the fixed cut-off only, as well as $72.5 \%$ of the participants with $\mathrm{AO}$ according to both cut-offs, did not report a diagnosis of any chronic respiratory disease (table 4).

The PPV for the diagnosis of chronic AO according to both cut-off values was low for all chronic respiratory symptoms together, as well as for chronic cough and dyspnoea separately (table 4). The PPV for chronic dyspnoea and cough for $\mathrm{AO}$ according to the fixed cut-off was significantly higher for men than for women (22.9 and 6.3\% for chronic dyspnoea and 19.4 and $6.5 \%$ for chronic cough, respectively). The PPV was significantly lower for the younger (35-54 years old) than the older age group (55-70 years old; 5.9 and $14.2 \%$ for any respiratory symp- toms; 5.1 and $16.2 \%$ for chronic cough; 5.36 and $13.52 \%$ for chronic dyspnoea, respectively).

\section{Discussion}

Main Findings and Comparison with Previous Research

In our population-based cross-sectional sample of adults aged 35-70 years in two north-western cities in Russia, post-BD AO according to the GLI-LLN was lower than for the fixed cut-off. AO based on both cut-offs was significantly associated with tobacco exposure, but not with occupational or indoor pollution. The PPV of all chronic respiratory symptoms for AO by both cut-off values (adjusted by sex and age) was low. 
AO Prevalence Using the Fixed and GLI-LLN Cut-Offs for $\mathrm{FEV}_{1} / \mathrm{FVC}$

The prevalence of COPD varies significantly across countries, ranging from 15.3 to $28.7 \%$ in men and from 7.6 to $25.7 \%$ in women (based on the fixed cut-off), and these differences are primarily due to the differences in smoking prevalence between the sexes [4].

A different prevalence for $\mathrm{AO}$ is reported in the literature based on the fixed or GLI-LLN cut-off $[22,23]$. The prevalence of $\mathrm{AO}$ in persons aged $40-95$ years in England and Wales is $2.8,22.2$ and $13.1 \%$ for diagnosed COPD, fixed-ratio and GLI-LLN values, respectively [23]. The gap in the prevalence between values based on the fixed and GLI-LLN cut-offs is higher in the older age groups. Among adults aged 40-79 years in the USA, the COPD prevalence using the fixed cut-off was $20.9 \%$ for pre-BD and $14.0 \%$ for post-BD values, while for the LLN it was 15.4 and $10.2 \%$, respectively [24].

In line with these previous studies, we observed that in north-western Russia, the AO prevalence by GLI-LLN was lower than by the fixed cut-off. Previous studies have reported a higher AO prevalence using both fixed and GLI-LLN cut-offs compared to our RESPECT study population, but their populations included more older adults (up to 79 or 95 years old) [23-25]. We also found that our participants with $\mathrm{AO}$ were more likely to be older, current smokers, and with more pack-years of smoking, and the gap in the prevalence between the fixed and LLN cut-offs increased in older age groups ( $0.4 \%$ for younger and $5.0 \%$ for older age groups, $\mathrm{p}<0.0001$ ).

Finding a relatively low prevalence of $\mathrm{AO}$ in the RESPECT population was unexpected but was supported by a sensitivity analysis. Additional research is needed in order to understand this. One possible explanation could be the huge cardiovascular mortality rate.

Similar to most developed countries, CVD is a leading cause of mortality in Russia, but the levels of CVD mortality in working-age Russian men and women are the highest in Europe. The CVD mortality is 38.8 and $36.8 \%$ for men and women aged 25-64 years, respectively. In St. Petersburg, the rate of deaths from CVD among men in this age category is $47.0 \%$, i.e. significantly higher than the average Russian mortality rate [26]. In the Arkhangelsk region, CVDs are the main cause of death at ages $<70$ years, and were responsible for $35 \%$ of all deaths in men and women. Both the absolute number of cardiovascular deaths and the age-standardized rates in men were more than twice those in women [27]. However, our findings should also be put in perspective of our population characteristics. In online supplementary appen- dix 3, we tried to make an age- and sex-stratified comparison with data available from other northern countries.

\section{Risk Factors for $A O$}

Tobacco smoking and outdoor, occupational or indoor pollution are major COPD risk factors $[4,6,28]$. In our population, only smoking was a risk factor for AO. Although cigarette smoke is widely acknowledged as the single most important risk factor for COPD, never-smokers may account for $25-33 \%$ of all COPD cases, with women being a substantial proportion of AO cases [4,29]. The predictors of COPD in never-smokers include age, education, exposure to occupational hazards, childhood respiratory diseases and BMI.

Our study demonstrated heterogeneity in the prevalence of AO between men and women, and this difference can be at least partly explained by sex differences in the prevalence of cigarette smoking. We observed a fairly high prevalence of AO in never-smokers, particularly in men $(4.6 \% \mathrm{AO}$ in male never-smokers and $2.7 \%$ in females, $\mathrm{p}<0.05)$. It is still contested whether women are at greater risk for COPD than men if they are equally exposed to smoking and other pollutants [30,31]. The current understanding of risk factors for COPD is in many aspects still incomplete; a better understanding of relations and interactions between risk factors as well as their contribution to COPD is crucial for developing the best prevention policies including smoking cessation $[4,6]$.

\section{Paradoxical BD Response and Overlap Syndrome}

In our study, we found that approximately $1 \%$ of the participants with normal pre-BD $\mathrm{FEV}_{1} / \mathrm{FVC}$ using both cut-offs converted to $\mathrm{AO}$ after $\mathrm{BD}$ administration. This significant reduction in lung function after the administration of a $\mathrm{BD}$ is termed paradoxical bronchoconstriction [32], and it has been previously reported to range between 0.5 and $1.5 \%$ according to the fixed and GLILLN cut-offs, respectively $[33,34]$. In another study, paradoxical responses were noted in 5\% of the patients, and their frequency was similar in those with COPD and in smokers without AO [35]. This phenomenon was also independently associated with COPD intermediate endpoints, including reduced exercise capacity, increased dyspnoea and a greater frequency of exacerbations, and the authors assume it is an enigmatic COPD phenotype [35].

A few possible explanations regarding a paradoxical (or negative) BD response can be forwarded, for example as an isolated increase in residual volume (a peripheral
Andreeva/Pokhaznikova/Lebedev/ Moiseeva/Kutznetsova/Degryse 
$\mathrm{AO}$ ) and a decrease in $\mathrm{FEV}_{1}$ (a bronchoconstriction that might be triggered by repeated maximum respiratory manoeuvres during spirometry) [36-38]. Additional research is needed in order to investigate this phenomenon, which appeared to be more frequent than we suspected.

Recently, it has been reported that approximately 15$45 \%$ of the population with obstructive airway disease may have asthma-COPD overlap syndrome [39]. In our population, we found reversible $\mathrm{AO}$ in $1.3 \%$ of all participants. We also observed a positive reversibility test in $22.5 \%(32 / 142)$ of those with post-BD AO by the fixed cut-off, suggesting that these participants may have asthma-COPD overlap syndrome, but this finding should be put in perspective of an additional clinical assessment [40].

\section{Predictive Value of Symptoms for AO}

The diagnosis of COPD is complex, including spirometry-based AO as well as symptoms and risk factors. Thus far, spirometry has been the basis for COPD diagnosis using a fixed or LLN cut-off of $\mathrm{FEV}_{1} / \mathrm{FVC}$, but neither of these cut-offs is able to fully characterize the complex diagnostic features of this disease [41]. An assessment of COPD, particularly for milder $\mathrm{AO}$, requires a comprehensive clinical and functional evaluation that cannot be limited to an $\mathrm{FEV}_{1} / \mathrm{FVC}$ value [42].

In addition, in patients with similar degrees of $\mathrm{AO}$, perceived symptoms and signs, such as dyspnoea and/or breathlessness, cough or mucus production, peripheral muscle weakness, exercise tolerance or physical capacity, can vary greatly [43].

The diagnostic value of clinical signs and symptoms for COPD is still contested [44, 45]. Price et al. [44] have reported on a simple self-administered patient questionnaire that could be used to identify patients exhibiting a high likelihood of COPD for whom spirometry testing would be important. Eight items in this questionnaire had significant relationships with COPD diagnosis, including age, pack-years, BMI, symptoms, wheezing frequency and history of allergies. Only one cough-related and one dyspnoea-related item significantly predicted COPD in a multivariate analysis [44]. Another study showed that the PPV was $12.2 \%$ when using only respiratory symptoms, but $43.5 \%$ when using symptoms with spirometry [45].

In our population-based study, we found a low PPV for symptoms regarding AO diagnosis (10.96\% for chronic respiratory symptoms, $11.24 \%$ for cough and $10.58 \%$ for dyspnoea), thus supporting the need for a comprehensive COPD diagnosis that includes spirometry.

Prevalence of COPD in North-Western Russia

\section{Strengths and Limitations}

The protocol of the RESPECT study enabled the collection of information about several potential risk factors for COPD including smoking, occupational exposure to dust, indoor exposure to biomass fuels used for home heating and cooking, tuberculosis and socioeconomic status considering validated international questionnaires. Spirometry was performed before and after the BD test and followed the ATS/ERS standards of spirometry quality. Our study is the first to report the prevalence of $\mathrm{AO}$ in a cohort population in north-western Russia using the recently published GLI 2012 reference values and comparing it with the fixed cut-off, as well as analysing predictors of $\mathrm{AO}$ and the diagnostic value of respiratory symptoms.

Our study has also some limitations. We restricted our sample population to individuals aged 35-70 years, because COPD develops over several decades of exposure to inhaled particulates, and our aim was to identify the early stages of COPD and AO.

The RESPECT study population differs from the total population of the north-western region of Russia in terms of age and sex [46]. It includes more women than the average population in the north-western region of Russia (68.2 vs. $55.3 \%$ ), as well as more participants aged $55-70$ years (53.7 vs. $35.3 \%)$. It also includes fewer current and ex-smokers than the average Russian population [47] (47.8 vs. $53.9 \%)$. These differences might have led to a discrete underestimation of the AO prevalence.

\section{Conclusion}

In a representative sample of adults aged $35-70$ years in north-western Russia, the prevalence of post-BD AO was higher when using the fixed rather than the GLI-LLN cut-off for $\mathrm{FEV}_{1} / \mathrm{FVC}$. Only tobacco smoking was an independent risk factor for $\mathrm{AO}$, while there was no association between $\mathrm{AO}$ by both cut-offs and reported exposure to occupational or indoor pollution. The diagnostic value of respiratory symptoms for AO by both cut-offs was low, supporting a comprehensive approach to diagnosing COPD which includes spirometry and the assessment of symptoms and risk factors.

\section{Acknowledgements}

The authors would like to thank all of the investigators from St. Petersburg and Arkhangelsk who made this study possible. 


\section{Financial Disclosure and Conflicts of Interest}

The RESPECT study was supported by an unconditional grant from AstraZeneca International to the Louvain Foundation, the support unit of the Universite Catholique de Louvain, which is charged with developing educational and research projects for the university by collecting gifts from corporations, foundations and alumni. None of the study sponsors played a role in the study design, data collection, data analysis, data interpretation, or writing of the report. The corresponding author had full access to all data in the study and had final responsibility for the decision to submit for publication.

The authors declare that they have no competing interests.

\section{References}

$>_{1}$ Bousquet J, Kiley J, Bateman ED, Viegi G, Cruz AA, Khaltaev N, Aït Khaled N, BaenaCagnani CE, Barreto ML, Billo N, Canonica GW, Carlsen KH, Chavannes N, Chuchalin A, Drazen J, Fabbri LM, Gerbase MW, Humbert M, Joos G, Masjedi MR, Makino S, Rabe K, To T, Zhi L: Prioritised research agenda for prevention and control of chronic respiratory diseases. Eur Respir J 2010;36:995-1001.

$\checkmark 2$ Steenbruggen I, Zielinski J, Lange P, Price D, Soriano JB: A BOLD statement on how to case-find moderate/severe COPD. Eur Respir J 2013;41:503-504.

- 3 Halbert RJ, Natoli JL, Gano A, Badamgarav E, Buist AS, Mannino DM: Global burden of COPD: systematic review and meta-analysis. Eur Respir J 2006;28:523-532.

-4 Buist AS, McBurnie MA, Vollmer WM, Gillespie S, Burney P, Mannino DM, Menezes AM, Sullivan SD, Lee TA, Weiss KB, Jensen RL, Marks GB, Gulsvik A, Nizankowska-Mogilnicka E; the BOLD Collaborative Research Group: International variation in the prevalence of COPD (the BOLD Study): a population-based prevalence study. Lancet 2007; 370:741-750

5 Lamprecht B, Soriano J, Studnicka M, Kaiser B, Vanfleteren L, Gnatiuc L, Burney P, Miravitlles M, García-Rio F, Akbari K, Ancochea J, Menezes AM, Perez-Padilla R, Montes de Oca M, Torres-Duque CA, Caballero A, González-García M, Buist S; the BOLD Collaborative Research Group, the EPI-SCAN Team, the PLATINO Team, and the PREPOCOL Study Group: Determinants of underdiagnosis of COPD in national and international surveys. Chest 2015;148:971-985.

6 The Global Strategy for the Diagnosis, Management and Prevention of COPD. Global Initiative for Chronic Obstructive Lung Disease (GOLD). 2015. http://www.goldcopd. org/ (last updated January 2015; accessed September 30, 2015).

7 Buffels J, Degryse J, Heyrman J, Decramer M: Office spirometry significantly improves early detection of COPD in general practice: the DIDASCO study. Chest 2004;125:1394-1399.

-8 Price DB, Tinkelman DG, Halbert RJ, Nordyke RJ, Isonaka S, Nonikov D, Juniper EF, Freeman D, Hausen T, Levy ML, Østrem A, van der Molen T, van Schayck CP: Symptombased questionnaire for identifying COPD in smokers. Respiration 2006;73:285-295.
-9 Kotz D, Nelemans P, van Schayck CP, Wesseling GJ: External validation of a COPD diagnostic questionnaire. Eur Respir J 2008;31: 298-303.

10 Burgel PR, Paillasseur JL, Caillaud D, TillieLeblond I, Chanez P, Escamilla R, Court-Fortune I, Perez T, Carré P, Roche N; the Initiatives BPCO Scientific Committee: Clinical COPD phenotypes: a novel approach using principal component and cluster analyses. Eur Respir J 2010;36:531-539.

11 Quanjer PH, Stanojevic S, Cole TJ, Baur X, Hall GL, Culver BH, Enright PL, Hankinson JL, Ip MS, Zheng J, Stocks J; the ERS Global Lung Function Initiative: Multi-ethnic reference values for spirometry for the 3-95-year age range: the global lung function 2012 equations. Eur Respir J 2012;40:1324-1343.

12 Quanjer PH: Correctly defining criteria for diagnosing chronic obstructive pulmonary disease matters. Am J Respir Crit Care Med 2014;189:230.

13 van Dijk WD, Gupta N, Tan WC, Bourbeau J: Clinical relevance of diagnosing COPD by fixed ratio or lower limit of normal: a systematic review. COPD 2014;11:113-120.

14 Chuchalin AG, Khaltaev N, Antonov NS, Galkin DV, Manakov LG, Antonini P, Murphy M, Solodovnikov AG, Bousquet J, Pereira MHS, Demko IV: Chronic respiratory diseases and risk factors in 12 regions of the Russian Federation. Int J Chron Obstruct Pulmon Dis 2014;9:963-974.

15 Andreeva E, Pokhaznikova M, Lebedev A, Moiseeva I, Kozlov A, Kuznetsova O, Degryse JM: The RESPECT study: RESearch on the PrEvalence and the diagnosis of COPD and its Tobacco-related etiology: a study protocol. BMC Public Health 2015;15:831.

16 Ferris BG: Epidemiology standardization project. II. Recommended respiratory disease questionnaires for use with adults and children in epidemiological research. Am Rev Respir Dis 1978;118:7-57.

17 Eisneret MD, Yelin EH, Katz PP, Earnest G, Blank PD: Exposure to indoor combustion and adult asthma outcomes: environmental tobacco smoke, gas stoves, and wood smoke. Thorax 2002;57:973-978.

18 Bridevaux PO, Probst-Hensch NM, Schindler C, Curjuric I, Felber Dietrich D, Braendli O, Brutsche M, Burdet L, Frey M, Gerbase MW, Ackermann-Liebrich U, Pons M, Tschopp
JM, Rochat T, Russi EW: Prevalence of airflow obstruction in smokers and never-smokers in Switzerland. Eur Respir J 2010;36:12591269.

19 Degryse J, Buffels J, Van Dijck Y, Decramer M, Nemery B: Accuracy of office spirometry performed by trained primary-care physicians using the MIR Spirobank hand-held spirometer. Respiration 2012;83:543-552.

20 Pokhaznikova MA, Kuznetsova OY, Andreeva EA, Moiseeva IE, Lebedev AK: Experience of development of distance learning course of spirometry in training of general practitioners (in Russian). Russian Fam Phys 2012;4: 39-44.

21 Miller MR, Hankinson J, Brusasco V, Burgos F, Casaburi R, Coates A, Crapo R, Enright P, van der Grinten CPM, Gustafsson P, Jensen R, Johnson DC, MacIntyre N, McKay R, Navajas D, Pedersen OF, Pellegrino R, Viegi G, Wanger J: Standardisation of spirometry. Eur Respir J 2005;26:319-338.

22 Global Lung Function Initiative. GLI-2012 desktop software for individual calculations. http://www.ers-education.org/guidelines/ global-lung-function-initiative/tools/gli2012-desktop-software-for-individual-calculations.aspx (last updated December 18, 2014; last accessed September 30, 2015).

23 Scholes S, Moody A, Mindell JS: Estimating population prevalence of potential airflow obstruction using different spirometric criteria: a pooled cross-sectional analysis of persons aged 40-95 years in England and Wales. BMJ Open 2014;4:e005685.

24 Tilert T, Dillon C, Paulose-Ram R, Hnizdo E, Doney B: Estimating the US prevalence of chronic obstructive pulmonary disease using pre- and post-bronchodilator spirometry: the National Health and Nutrition Examination Survey (NHANES) 2007-2010. Respir Res 2013;14:103.

25 Vanfleteren LE, Franssen FM, Wesseling G, Wouters EF: The prevalence of chronic obstructive pulmonary disease in Maastricht, the Netherlands. Respir Med 2012;106:871874.

26 Shalnova SA, Konradi AO, Karpov Yu A, Kontsevaya AV, Deev AD, Kapustina AV, Khudyakov MB, Shlyakhto EV, Boytsov SA: Cardiovascular mortality in 12 Russian Federation regions. Russian J Cardiol 2012;5:611. 
-27 Sidorenkov O, Nilssen O, Nieboer E, Kleshchinov N, Grjibovski AM: Premature cardiovascular mortality and alcohol consumption before death in Arkhangelsk, Russia: an analysis of a consecutive series of forensic autopsies. Int J Epidemiol 2011;40:1519-1529.

28 Salvi SS, Barnes PJ: Chronic obstructive pulmonary disease in non-smokers. Lancet 2009; 374:733-743.

29 Lamprecht B, McBurnie MA, Vollmer WM, Gudmundsson G, Welte T, NizankowskaMogilnicka E, Studnicka M, Bateman E, Anto JM, Burney P, Mannino DM, Buist SA; the BOLD Collaborative Research Group: COPD in never smokers: results from the population-based burden of obstructive lung disease study. Chest 2011;139:752-763.

- 30 de Torres JP, Casanova C, Hernandez C, Abreu J, Aguirre-Jaime A, Celli BR: Gender and COPD in patients attending a pulmonary clinic. Chest 2005;128:2012-2016.

- 31 Silverman EK, Weiss ST, Drazen JM, Chapman HA, Carey V, Campbell EJ, Denish P, Silverman RA, Celedon JC, Reilly JJ, Ginns LC, Speizer FE: Gender-related differences in severe, early-onset chronic obstructive pulmonary disease. Am J Respir Crit Care Med 2000; 162:2152-2158.

32 Kirby M, Parraga G: Paradoxical response to bronchodilators in COPD: curious enigma or clinically important phenotype? Lancet Respir Med 2014;2:865-867.

-33 Hegewald MJ, Townsend RG, Abbott JT, Crapo RO: Bronchodilator response in patients with normal baseline spirometry. Respir Care 2012;57:1564-1570.
34 Johannessen A, Omenaas ER, Bakke PS, Gulsvik A: Implications of reversibility testing on prevalence and risk factors for chronic obstructive pulmonary disease: a community study. Thorax 2005;60:842-847.

35 Bhatt SP, Wells JM, Kim V, Criner GJ, Hersh CP, Hardin M, Bailey WC, Nath H, Kim YI, Foreman MG, Stinson DS, Wilson CG, Rennard SI, Silverman EK, Make BJ, Dransfield MT; the COPDGene Investigators: Radiological correlates and clinical implications of the paradoxical lung function response to $\beta_{2}$ agonists: an observational study. Lancet Respir Med 2014;2:911-918.

36 Roncoroni AJ, Goldman E, Puy RJ, Mancino $\mathrm{M}$ : Bronchoconstriction induced by repeated forced vital capacity manoeuvres. Acta Allergol 1975;30:375-389.

37 Cerveri I, Pellegrino R, Dore R, Corsico A, Fulgoni P, van de Woestijne KP, Brusasco V: Mechanisms for isolated volume response to a bronchodilator in patients with COPD. J Appl Physiol 2000;88:1989-1995.

38 Schermer T, Heijdra Y, Zadel S, van den Bemt L, Boonman-de Winter L, Dekhuijzen R, Smeele I: Flow and volume responses after routine salbutamol reversibility testing in mild to very severe COPD. Respir Med 2007; 101:1355-1362.

39 Postma DS, Rabe KF: The asthma-COPD overlap syndrome. N Engl J Med 2015;373: 1241-1249.

40 Diagnosis of Diseases of Chronic Airflow Limitation: Asthma, COPD and AsthmaCOPD Overlap Syndrome (ACOS). http:// www.ginasthma.org/documents/14 (last updated April 2015; last accessed September 30, 2015)
41 Clini EM, Crisafulli E, Roca M, Malerba M: Diagnosis of chronic obstructive pulmonary disease, simpler is better. Complexity and simplicity. Eur J Intern Med 2013;24:195198.

42 Di Marco F, Tantucci C, Pellegrino G, Centanni S: Chronic obstructive pulmonary disease diagnosis: the simpler the better? Not always. Eur J Intern Med 2013;24:199-202.

43 Waatevik M, Johannessen A, Hardie JA, Bjordal JM, Aukrust P, Bakke PS, Eagan TM: Different COPD disease characteristics are related to different outcomes in the 6-minute walk test. COPD 2012;9:227-234.

44 Price DB, Tinkelman DG, Halbert RJ, Nordyke RJ, Isonaka S, Nonikov D, Juniper EF, Freeman D, Hausen T, Levy ML, Østrem A, van der Molen T, van Schayck CP: Symptombased questionnaire for identifying COPD in smokers. Respiration 2006;73:285-295.

45 Quint JK, Müllerova H, DiSantostefano RL, Forbes H, Eaton S, Hurst JR, Davis K, Smeeth L: Validation of chronic obstructive pulmonary disease recording in the Clinical Practice Research Datalink (CPRD-GOLD). BMJ Open 2014;4:e005540.

46 The Russian Population Census. 2010. http:// www.gks.ru/free_doc/new_site/perepis2010/ croc/perepis_itogi1612.htm (last updated 2013; last accessed September 30, 2015).

47 WHO: Global Adult Tobacco Survey (GATS): Russian Federation 2009. Country report. http://www.who.int/tobacco/surveillance/ russian_federation/en/ (last updated November 9, 2010; last accessed September 30, 2015). 